\title{
Heart Rate Recovery in Metabolically Healthy Obesity and Metabolically Unhealthy Obesity Korean Adults
}

\author{
Kyung-A Shin ${ }^{\dagger}, *$ \\ Department of Clinical Laboratory Science, Shinsung University, Dangjin 31801, Korea
}

\begin{abstract}
Heart rate recovery (HRR) is simply an indicator of autonomic balance and is a useful physiological indicator to predict cardiovascular morbidity and mortality. The purpose of this study was to compare the differences in HRR between metabolically healthy obesity group and metabolically unhealthy obesity and to ascertain whether heart rate recovery is a predictor of metabolic syndrome. Metabolic syndrome was defined according to the standards of the National Cholesterol Education Program Adult Care Panel III. Obesity was assessed according to WHO Asian criteria. It was classified into three groups of metabolically healthy non-obesity group (MHNO, n=113), metabolically healthy obesity group (MHO, $\mathrm{n}=66$ ), metabolically unhealthy obesity (MUO, $n=18$ ). Exercise test was performed with Bruce protocol using a treadmill instrument. There was no difference in HRR between MHO and MUO (32.71 \pm 12.25 vs 25.53 \pm 8.13$)$, but there was late HRR in MUO than MHNO (25.53 \pm 8.13 vs $34.51 \pm 11.80)$. HRR in obese was significantly correlated with BMI $(r=-0.342, P=0.004)$, waist circumference $(r=-0.246, \mathrm{P}=0.043)$, triglyceride $(r=-0.350, P=0.003), \mathrm{HbA1c}(r=-0.315$, $P=0.009)$, insulin $(r=-0.290, P=0.017)$ and uric acid $(r=-0.303, P=0.012)$. HRR showed a lower prevalence of abdominal obesity, hypertriglyceridemia, and low HDL-cholesterol in the third tertile than in the first tertile. In conclusion, MHO had no difference in vagal activity compared with MHNO, but MUO had low vagal activity. HRR is associated with metabolic parameters and is a useful predictor of abdominal obesity, hypertriglyceridemia, and low HDL-cholesterolemia
\end{abstract}

Key Words: Heart rate recovery, MHO, MUO

\section{서 론}

자율신경계 기능장애는 비만을 포함한 대사증후군 구성 요소 및 심폐체력과 관련이 있는 심혈관계 위험인자이다 (Bjelakovic et al., 2017). 또한 교감신경의 활성 증가와 부 교감신경의 활성도 감소에 따른 자율신경계 조절능력의 저하는 대사이상을 예측한다고 보고된다(Berntson et al., 2008; Licht et al., 2013). 심박수 회복(heart rate recovery, $\mathrm{HRR}$ )은 간단하게 자율신경계 균형을 검증하는 지표이며, 심혈관질환의 이환율 및 사망률을 예측하는데 유용한 생
리적 지표이다(Peçanha et al., 2014; Yu et al., 2016). 심박수 회복은 운동 직후의 자율신경계 변화를 반영하며, 최대 심박수와 운동 후 1 분대 심박수의 차이로 정의되는 부교 감신경 재활성도를 나타낸다(Shetler et al., 2001; Kim et al., 2011). 또한 대사증후군은 자율신경계 기능장애와 함께 심 혈관질환 위험을 증가시키는 요인으로 제시되며, 국내에 서 성인을 대상으로 파악한 대사증후군 유병률은 1998년 $24.9 \%$ 에서 2007 년에는 $31.3 \%$ 로 증가하는 추세를 보인다 (Curtis and O'Keefe, 2002; Libby et al., 2002; Lim et al., 2011). 대사증후군의 심박수 회복에 대한 Shin (2011)의 연구결과 에 따르면 30세 이상 성인을 대상으로 대사증후군 위험

Received: June 7, 2018 / Revised: July 11, 2018 / Accepted: September 7, 2018

* Professor.

${ }^{\dagger}$ Corresponding author: Kyung-A Shin. Department of Clinical Laboratory Science, Shinsung University, 1 Daehak-ro, Jeongmi-myeon, Dangjin 31801, Korea. Tel: +82-41-350-1408, Fax:+82-41-350-1355, e-mail: mobitz2@hanmail.net

(C) The Korean Society for Biomedical Laboratory Sciences. All rights reserved.

(C) This is an Open Access article distributed under the terms of the Creative Commons Attribution Non-Commercial License (http://creativecommons.org/licenses/by-nc/3.0/) which permits unrestricted non-commercial use, distribution, and reproduction in any medium, provided the original work is properly cited. 
요인이 없는군 보다 대사증후군 진단군에서 늦은 심박수 회복을 보인다고 보고하였으며, 유사하게 Singh과 Shen (2013)은 청소년을 대상으로 정상 체중보다 과체중 청소 년에서 미주신경 활성도의 감소로 인해 심박수 회복이 느 리다는 결과를 제시하였다. 반면 마른 체형과 비만 체형 의 최대 운동 후 심박수 회복과 심박동수 변이(heart rate variability)에는 차이가 없다는 일관되지 않은 결과가 보고 된다(Guilkey et al., 2017).

한편, 체질량지수(body mass index, BMI)를 기준으로 과 체중이나 비만인은 이상지질혈증, 고혈압 및 당뇨병과 같 은 대사합병증의 유병율이 높으나, 모든 과체중과 비만 인에서 대사적으로 이상을 나타내는 것은 아니다(Grundy, 2004; Dorresteijn et al., 2012). 과체중 또는 비만인의 18 $44 \%$ 는 인슐린 감수성이 높고 당뇨병, 이상지질혈증, 고혈 압, 낮은 염증 및 간 효소치를 보여 이러한 사람을 대사적 으로 건강한 비만인(metabolically healthy obesity, $\mathrm{MHO}$ )이 라고 규정하고 있다(Primeau et al., 2011). 하지만 비만인에 서 느린 심박수 회복을 보이는 것에 대한 명확한 증거는 부족하며, 국내에서는 대사적으로 건강한 비만군과 대사 적으로 이상이 있는 비만군을 구분하여 심박수 회복과의 관계를 확인한 연구는 제한적이다. 또한 아시아인은 백인 과 비교하여 BMI가 낮지만 심혈관질환의 발생 위험은 더 높은 것으로 보고되고 있어 서구인을 대상으로 한 연구결 과를 국내에 적용하기에 어려움이 있다(Deurenberg et al., 1998).

본 연구의 목적은 대사적으로 건강한 비만군과 대사적 으로 이상이 있는 비만군간에 자율신경계 이상을 간단하 게 검증할 수 있는 지표인 심박수 회복의 차이를 비교하 고 심박수 회복이 대사증후군 발병을 예측하는 지표인지 를 확인하고자 하였다.

\section{재료 및 방법}

\section{연구 대상자 및 대사증후군 진단기준}

본 연구의 대상자는 2016년 3월부터 2018년 3월까지 경기소재 일개 종합병원 종합검진센터에서 운동부하검사 를 받은 20세 이상의 성인을 연구 대상으로 하였다. 전체 대상자 210 명 중 심박수에 영향을 미치는 약제를 복용 중 인 자, 신체 계측치 및 혈액검사 수치가 누락된 자, 외국 인 대상자를 제외한 최종 연구에 포함된 대상자는 197명 이었다. 복용 중인 약제에 대한 정보는 자기기입식 설문 지를 통해 얻었으며, 본 연구는 경기소재 종합병원에서
기관생명윤리위원회의 심의를 받아 시행되었다. 대사증후 군은 NCEP-ATP III (Executive Summary of The Third Report of The National Cholesterol Education Program Adult Treatment Panel III) 기준에 따라 5 가지 항목 중 3 가지 이상 해당하 는 경우 대사적으로 이상이 있다고 판정하였다(National Cholesterol Education Program-Adult Treatment Panel III, 2001). 대사증후군 진단기준 중 복부비만은 아시아인의 기준을 적용하였다(WHO, 2000). 또한 세계보건기구에서 제시한 아시아인의 기준에 따라 BMI $\geq 25 \mathrm{~kg} / \mathrm{m}^{2}$ 인 경우 비만으로 판정하였으며, 정상 체중은 $18.5 \sim 22.9 \mathrm{~kg} / \mathrm{m}^{2}$ 로 정의하였다 (WHO, 2000). 이상의 대사증후군과 비만의 정의에 따라 대사적으로 건강한 정상 체중군(metabolically healthy nonobesity, MHNO, $\mathrm{n}=113$ ), 대사적으로 건강한 비만군(metabolically healthy obesity, $\mathrm{MHO}, \mathrm{n}=66$ ), 대사적으로 이상이 있는 비만군(metabolically unhealthy obesity, MUO, n=18)으 로 집단을 분류하였다(Oh et al., 2006).

\section{신체 계측 및 혈액검사}

DS-103M (Jenix, Seoul, Korea) 자동 신체 계측기를 사용 하여 신장과 체중을 계측하였으며, BMI는 체중 $(\mathrm{kg}) /$ \{신 장 $\left.\left(\mathrm{m}^{2}\right)\right\}$ 로 계산하여 제시하였다. 허리둘레는 양발을 25 $30 \mathrm{~cm}$ 정도 벌리고 숨을 내쉰 상태로 갈비뼈 가장 아래 부분과 골반의 가장 높은 위치인 장골능의 중간부위를 줄자로 측정하였다. 엉덩이 둘레는 엉덩이의 가장 돌출된 지점을 지나 수평으로 측정하였고 허리둔부비(waist to hip ratio, WHR)는 허리둘레를 엉덩이 둘레로 나눈 값으로 하였다. 혈압은 10 분 정도 안정을 취한 후 수은 혈압계 (HICO, Tokyo, Japan)로 10분 간격으로 2회 측정하여 평균 값을 적용하였다. 혈액분석은 8시간 이상 공복 후 전주정 맥(antecubital vein)에서 채혈하여 총콜레스테롤, 중성지방, $\mathrm{HDL}$-콜레스테롤, LDL (low density lipoprotein)-콜레스테 롤, 공복혈당, 요산, 고감도 C-반응 단백(high sensitivity Creactive protein, hs-CRP), 호모시스테인을 자동생화학분석 기 TBA-200FR NEO (Toshiba, Tokyo, Japan)로 측정하였다. 당화혈색소(hemoglobin Alc, HbAlc)는 Variant II (Bio-Rad, CA, USA)로 HPLC (high performance liquid chromatography, HPLC)법으로 측정하였다. 인슐린은 Modular Analytics E170 (Roche, Mannheim, Germany) 장비로 ECLIA (electrochemiluminescence immunoassay)의 원리로 검사하였으며, 모든 혈액검사는 경기소재 종합병원 진단검사의학과에서 직접 분석하였다. 


\section{운동부하검사}

운동부하검사는 treadmill (Medtrack ST 55, Quinton Instrument Co., USA) 기구로 Bruce protocol에 따라 증상 제한 성(symptom limited) 운동부하를 시행하였다. Bruce protocol 은 3 분 간격으로 회전속도와 경사도에 의해 운동 단계별 (stage) 부하량을 증가시키는 방법이다. 운동직전과 운동 중 3 분 간격으로 심전도, 혈압, 심박수를 기록하였으며, 운 동 후 회복기는 1 분, 3 분, 5 분대에 심전도, 혈압, 심박수를 측정하였다. 운동부하검사 중 심박수와 심전도 측정은 12 채널 Quinton stress test system $(\mathrm{Q} 4500$, Quinton Instrument Co., USA)으로 측정하였으며, 220 에서 검사자의 나이를 뺀 최대 심박수의 85 90\% 이상 도달할 때까지 운동부하 검사를 시행하였다. 또한 운동강도는 대사당량(metabolic equivalents, MET)으로 구하였으며, treadmill 속도와 경사도
를 이용하여 구하였다. 운동 후 회복기 반응은 treadmill 경사도 $0 \%$, 속도 $1.3 \mathrm{mph}$ 로 하여 30 40초간 걷게 하고, treadmill이 완전히 정지한 다음 침대에 누워 5 분 동안 심 전도, 혈압, 심박수의 회복 반응을 기록하였다. 심박수 회 복(heart rate recovery, HRR)은 운동부하검사시 도달한 최대 심박수에서 1 분대 회복기 심박수를 뺀 값으로 계산하였다 (Cole et al., 1999). 최대 심박수 및 혈압은 운동시, 회복기 동안에 가장 높은 심박수 및 혈압으로 정의하였다.

\section{자료처리방법}

통계분석은 SPSS Windows 21.0 (IBM, Armonk, USA) 프 로그램으로 분석하였다. $\mathrm{MHNO}, \mathrm{MHO}, \mathrm{MUO}$ 군의 세 집단 간 인체측정 변인, 생화학적 변인 및 심박수 회복을 포함 한 운동부하검사에 따른 혈역학적 반응의 차이를 확인하 기 위해 일원분산분석(one-way ANOVA)을 시행하였으며,

Table 1. Anthropometric and biochemical characteristics of the study subjects according to obesity phenotype

\begin{tabular}{|c|c|c|c|c|}
\hline Variables & MHNO (n=113) & MHO $(n=66)$ & MUO (n=18) & $P$-value \\
\hline Age (years) & $46.30 \pm 10.51$ & $49.19 \pm 9.32$ & $51.22 \pm 6.72$ & 0.050 \\
\hline Sex $(\text { male, } \%)^{\S}$ & $72(63.7)$ & $55(83.3)$ & $14(77.8)$ & 0.016 \\
\hline Height (cm) & $165.58 \pm 8.80$ & $167.45 \pm 8.72$ & $168.36 \pm 8.63$ & 0.245 \\
\hline Weight (kg) & $60.58 \pm 8.21$ & $75.51 \pm 10.30^{*}$ & $81.50 \pm 10.91^{* \dagger}$ & $<0.001$ \\
\hline BMI $\left(\mathrm{kg} / \mathrm{m}^{2}\right)$ & $21.99 \pm 1.67$ & $26.84 \pm 2.04^{*}$ & $28.72 \pm 2.53^{* \dagger}$ & $<0.001$ \\
\hline $\mathrm{WC}(\mathrm{cm})$ & $76.95 \pm 6.70$ & $87.30 \pm 6.26^{*}$ & $93.88 \pm 6.72^{* \dagger}$ & $<0.001$ \\
\hline $\mathrm{HC}(\mathrm{cm})$ & $91.52 \pm 4.71$ & $98.07 \pm 3.93^{*}$ & $101.43 \pm 8.03^{* \dagger}$ & $<0.001$ \\
\hline WHR & $0.85 \pm 0.06$ & $0.93 \pm 0.04^{*}$ & $0.95 \pm 0.05^{*}$ & $<0.001$ \\
\hline SBP (mmHg) & $109.77 \pm 13.09$ & $117.80 \pm 14.19^{*}$ & $123.05 \pm 13.51^{*}$ & $<0.001$ \\
\hline DBP (mmHg) & $71.32 \pm 9.91$ & $76.66 \pm 9.29^{*}$ & $82.50 \pm 11.66^{*}$ & $<0.001$ \\
\hline $\mathrm{TC}(\mathrm{mg} / \mathrm{dL})$ & $195.01 \pm 30.51$ & $212.33 \pm 37.99^{*}$ & $197.05 \pm 30.58$ & 0.004 \\
\hline $\mathrm{TG}(\mathrm{mg} / \mathrm{dL})$ & $111.94 \pm 66.02$ & $131.43 \pm 68.76$ & $217.83 \pm 103.14^{* \dagger}$ & $<0.001$ \\
\hline HDL-C (mg/dL) & $55.36 \pm 13.66$ & $51.34 \pm 11.41$ & $43.61 \pm 11.35^{*}$ & 0.001 \\
\hline LDL-C (mg/dL) & $121.76 \pm 27.54$ & $141.13 \pm 34.31^{*}$ & $123.61 \pm 31.06$ & $<0.001$ \\
\hline Glucose (mg/dL) & $92.01 \pm 17.54$ & $94.48 \pm 9.98$ & $112.50 \pm 24.04^{* \dagger}$ & $<0.001$ \\
\hline HbAlc (\%) & $5.71 \pm 0.65$ & $5.73 \pm 0.40$ & $6.48 \pm 0.81^{* \dagger}$ & $<0.001$ \\
\hline Insulin $(\mu \mathrm{U} / \mathrm{mL})$ & $4.74 \pm 2.74$ & $7.51 \pm 4.07^{*}$ & $10.69 \pm 6.10^{* \dagger}$ & $<0.001$ \\
\hline Uric acid (mg/dL) & $5.17 \pm 1.40$ & $5.88 \pm 1.30^{*}$ & $6.15 \pm 1.36^{*}$ & 0.001 \\
\hline hs-CRP (mg/dL) & $0.16 \pm 0.40$ & $0.30 \pm 0.86$ & $0.22 \pm 0.17$ & 0.363 \\
\hline Homocysteine & $12.09 \pm 3.64$ & $13.19 \pm 4.07$ & $12.83 \pm 3.21$ & 0.171 \\
\hline
\end{tabular}

Calculated by one way ANOVA and Scheffe test. Values are presented as mean $\pm \mathrm{SD}$.

${ }^{*}$ Significantly different from MHNO at $P<0.05,{ }^{\dagger}$ Significantly different from MHO at $P<0.05 .{ }^{\S}$ Calculated by $\chi^{2}$-test. Data are presented as number (\%). Abbreviation: MHNO, metabolically healthy non obesity; MHO, metabolically healthy obesity; MUO, metabolically unhealthy obesity; BMI, body mass index; WC, waist circumference; HP, hip circumference; WHR, waist hip ratio; SBP, systolic blood pressure; DBP, diastolic blood pressure; TC, total cholesterol; TG, triglyceride; HDL-C, high density lipoprotein cholesterol; LDL-C, low density lipoprotein cholesterol; HbA1c, hemoglobin A1c; hs-CRP, high sensitivity C-reactive protein. 
사후검정은 Scheffe 검정방법을 적용하였다. 또한 카이제 곱 검정(chi-square test)을 통해 세 집단간 성별에 차이가 있는지를 확인하였다. 심박수 회복과 대사증후군 관련 지 표들간의 관련성을 알아보기 위해 성별과 연령을 보정한 후 상관관계(correlation coefficient) 분석을 시행하였으며, 심박수 회복을 삼분위수로 나누어 대사증후군 및 대사증 후군 구성요소의 발병 위험을 알아보기 위해 성별과 연령 을 보정한 후 로지스틱 회귀(logistic regression) 분석을 실 시하였다. 모든 통계적 유의수준은 $P<0.05$ 로 정하였다.

\section{결 과}

\section{집단간 인체측정 및 생화학적 지표}

이 연구에서는 대상자를 $\mathrm{MHNO}, \mathrm{MHO}, \mathrm{MUO}$ 군으로 분류하여 집단간 인체측정 및 생화학적 지표의 차이를 비 교한 결과 Table 1 과 같다. 연령은 집단간 차이가 없었으 나, 성별은 $\mathrm{MHNO}, \mathrm{MHO}, \mathrm{MUO}$ 세 집단간 차이가 있었다 $(P=0.016)$. 체중, $\mathrm{BMI}$, 허리둘레, 엉덩이 둘레는 $\mathrm{MHNO}$ 군보다 $\mathrm{MHO}$ 군과 $\mathrm{MUO}$ 군이 높았으며, $\mathrm{MUO}$ 군은 $\mathrm{MHO}$ 군보다 높았다(모두 $P<0.001)$. WHR, 수축기와 이완기 혈 압은 $\mathrm{MHNO}$ 군보다 $\mathrm{MHO}$ 군과 $\mathrm{MUO}$ 군이 높았다(모두 $P<$ $0.001)$. 총콜레스테롤 $(P=0.004)$ 과 $\mathrm{LDL}-$ 콜레스테롤 $(P<0.001)$ 은 $\mathrm{MHNO}$ 군보다 $\mathrm{MHO}$ 군이 높았다. 중성지방, 공복혈당, $\mathrm{HbAlc}$ 는 $\mathrm{MHNO}$ 군과 $\mathrm{MHO}$ 군보다 $\mathrm{MUO}$ 군이 높았다(모두 $P<0.001)$. 인슐린은 $\mathrm{MHNO}$ 군보다 $\mathrm{MHO}$ 군과 $\mathrm{MUO}$ 군이 높았으며, $\mathrm{MUO}$ 군은 $\mathrm{MHO}$ 군보다 높았다 $(P<0.001)$. 요산 은 $\mathrm{MHNO}$ 군보다 $\mathrm{MHO}$ 군과 $\mathrm{MUO}$ 군에서 높게 나타났다
$(P=0.001) . \mathrm{HDL}$-콜레스테롤은 $\mathrm{MHNO}$ 군보다 $\mathrm{MUO}$ 군이 낮 았으며 $(P=0.001), \mathrm{hs}-\mathrm{CRP}$ 와 호모시스테인은 집단간 차이 가 없었다.

\section{집단간 운동부하검사에 따른 혈역학적 반응}

집단간 운동부하검사에 따른 혈액학적 반응의 차이를 비교한 결과 운동지속시간은 $\mathrm{MHNO}$ 군과 $\mathrm{MHO}$ 군보다 $\mathrm{MUO}$ 군이 낮게 나타났으나 $(P=0.047), \mathrm{MET}$ 는 집단간 차

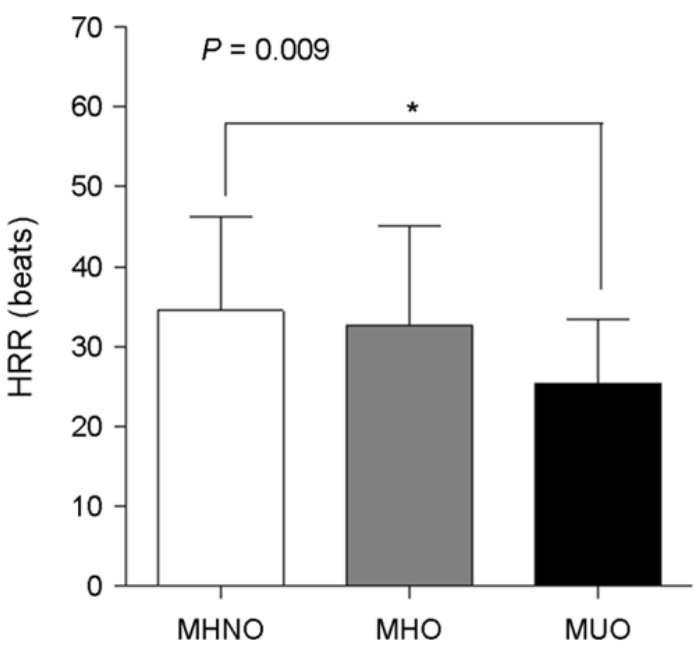

Fig. 1. Difference of HRR of MHNO, MHO and MUO groups MHNO (34.51 \pm 11.80$)$, MHO (32.71 \pm 12.25$)$, MUO (25.53 \pm 8.13$)$ *Significantly different from MHNO at $P<0.05$. Abbreviation: MHNO, metabolically healthy non obesity; MHO, metabolically healthy obesity; MUO, metabolically abnormal obesity; HRR, heart rate recovery.

Table 2. Exercise capacity and haemodynamic parameters of the study subjects according to obesity phenotype

\begin{tabular}{lcccc}
\hline \hline \multicolumn{1}{c}{ Variables } & MHNO $(\mathrm{n}=113)$ & MHO $(\mathrm{n}=66)$ & MUO $(\mathrm{n}=18)$ & $P$-value \\
\hline Exercise duration (min) & $9.89 \pm 1.66$ & $9.57 \pm 2.00$ & $8.81 \pm 1.39^{*}$ & 0.047 \\
Exercise capacity (MET) & $11.96 \pm 1.80$ & $11.50 \pm 2.23$ & $10.92 \pm 1.49$ & 0.064 \\
Rest HR (beats/min) & $63.52 \pm 11.46$ & $60.66 \pm 7.57$ & $63.55 \pm 11.18$ & 0.187 \\
Rest SBP (mmHg) & $116.46 \pm 14.35$ & $121.83 \pm 14.39^{*}$ & $125.22 \pm 12.84^{*}$ & 0.009 \\
Rest DBP (mmHg) & $72.89 \pm 11.18$ & $76.40 \pm 10.83$ & $82.61 \pm 11.05^{*}$ & 0.001 \\
Max HR (beats/min) & $164.26 \pm 13.98$ & $157.48 \pm 17.62^{*}$ & $151.88 \pm 13.70^{*}$ & 0.001 \\
Max SBP (mmHg) & $160.99 \pm 18.75$ & $170.04 \pm 24.11^{*}$ & $173.88 \pm 25.19^{*}$ & 0.005 \\
Max DBP (mmHg) & $79.40 \pm 11.58$ & $81.78 \pm 11.22$ & $85.05 \pm 11.34$ & 0.101 \\
\hline
\end{tabular}

Calculated by one way ANOVA and Scheffe test. Values are presented as mean \pm SD.

${ }^{*}$ Significantly different from MHNO at $P<0.05,{ }^{\dagger}$ Significantly different from MHO at $P<0.05$. Abbreviation: MHNO, metabolically healthy non obesity; MHO, metabolically healthy obesity; MUO, metabolically unhealthy obesity; obesity; MHO, metabolically healthy obesity; MUO, metabolically abnormal obesity; MET, metabolic equivalents; SBP, systolic blood pressure; DBP, diastolic blood pressure; HR, heart rate; HRR, heart rate recovery. 
이가 없었다. 안정시 수축기 혈압 $(P=0.009)$ 과 최대 심박 수 $(P=0.001)$, 최대 수축기 혈압 $(P=0.005)$ 은 $\mathrm{MHNO}$ 군보다 $\mathrm{MHO}$ 군과 $\mathrm{MUO}$ 군이 높았으며, 안정시 이완기 혈압은 MHNO군과 $\mathrm{MHO}$ 군보다 MUO군이 높았다 $(P=0.001)$ (Table 2). 또한 심박수 회복은 $\mathrm{MUO}$ 군보다 $\mathrm{MHO}$ 군이 높은 경 향을 보였으나 통계적 유의성은 없었으며, $\mathrm{MHNO}$ 군보다 $\mathrm{MUO}$ 군이 낮게 나타났다 $(P=0.009)$ (Fig. 1).

\section{비만군에서 심박수 회복과 대사증후군 관련 지표들간의 상관성}

연령과 성별을 보정한 후 비만군에서 심박수 회복과 대 사증후군 관련 지표들간의 상관관계를 분석한 결과 BMI ( $r=-0.342, P=0.004)$, 허리둘레 $(r=-0.246, P=0.043), \mathrm{HbAlc}$ $(r=-0.315, P=0.009)$, 인슐린 $(r=-0.290, P=0.017)$, 요산 $(r=-$

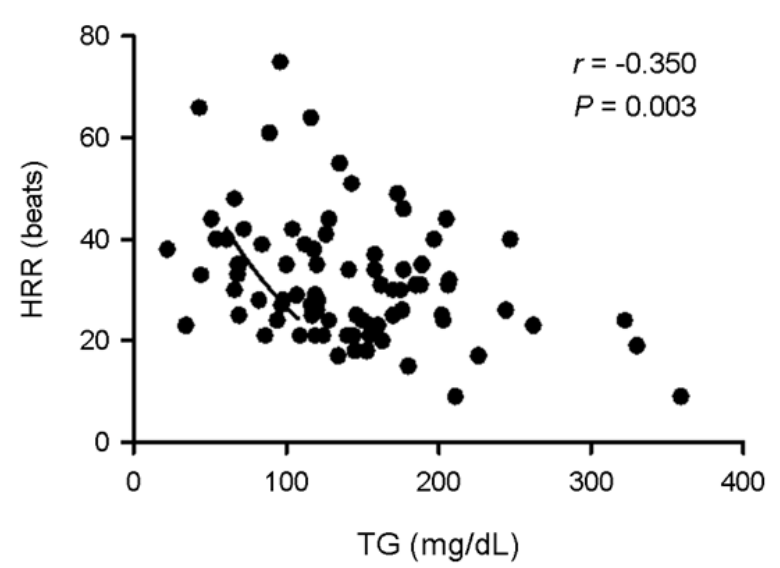

Fig. 2. Age and gender adjusted correlations between the heart rate recovery and triglyceride in obese. Abbreviation: TG, triglyceride; HRR, heart rate recovery.
$0.303, P=0.012)$, 중성지방 $(r=-0.350, P=0.003)$ 은 심박수 회 복과 유의한 역상관 관계를 나타냈다(Table 3) (Fig. 2).

\section{심박수 회복 삼분위수에 따른 대사증후군 및 대사증후 군 구성요소의 발병 위험}

연령과 성별을 보정한 후 심박수 회복 삼분위수에 따른 대사증후군 및 대사증후군 구성요소에 대한 교차비(odds ratio)와 95\% 신뢰구간(confidence interval, CI)을 Table 4에 제시하였다. 증가된 허리둘레는 심박수 회복의 제 1 삼분위 수보다 제 3 삼분위수에서 0.27 배(95\% CI: 0.103 0.690), 높

Table 3. Age and gender adjusted correlations the heart rate recovery and metabolic parameters in obese

\begin{tabular}{lcc}
\hline \hline \multirow{2}{*}{$\begin{array}{c}\text { Metabolic } \\
\text { parameters }\end{array}$} & \multicolumn{2}{c}{ HRR (beats) } \\
\cline { 2 - 3 } BMI $\left(\mathrm{kg} / \mathrm{m}^{2}\right)$ & Correlation coefficient & $P$-value \\
WC $(\mathrm{cm})$ & -0.342 & 0.004 \\
$\mathrm{SBP}(\mathrm{mmHg})$ & -0.246 & 0.043 \\
$\mathrm{DBP}(\mathrm{mmHg})$ & 0.015 & 0.904 \\
$\mathrm{TC}(\mathrm{mg} / \mathrm{dL})$ & -0.107 & 0.385 \\
$\mathrm{HDL}-\mathrm{C}(\mathrm{mg} / \mathrm{dL})$ & 0.065 & 0.596 \\
LDL-C $(\mathrm{mg} / \mathrm{dL})$ & 0.147 & 0.230 \\
Glucose $(\mathrm{mg} / \mathrm{dL})$ & 0.088 & 0.478 \\
HbA1c $(\%)$ & -0.215 & 0.078 \\
Insulin $(\mu \mathrm{U} / \mathrm{mL})$ & -0.315 & 0.009 \\
Uric acid $(\mathrm{mg} / \mathrm{dL})$ & -0.290 & 0.017 \\
\hline
\end{tabular}

Abbreviation: HRR, heart rate recovery; BMI, body mass index; SBP, systolic blood pressure; DBP, diastolic blood pressure; TC, total cholesterol; TG, triglyceride; HDL-C, high density lipoprotein cholesterol; LDL-C, low density lipoprotein cholesterol; HbAlc, hemoglobin Alc.

Table 4. Adjusted odds ratios (OR) and $95 \%$ confidence intervals (CI) of the HRR associated with metabolic syndrome components

\begin{tabular}{lccc}
\hline \hline \multirow{2}{*}{ Metabolic parameter } & \multicolumn{3}{c}{ HRR (beats) } \\
\cline { 2 - 4 } & $1^{\text {st }}$ Tertile & $2^{\text {nd }}$ Tertile & $3^{\text {rd }}$ Tertile \\
\hline Large waist circumference & 1.00 (Reference) & $0.513(0.222 \sim 1.187)$ & $0.266(0.103 \sim 0.690)^{*}$ \\
High triglyceride level & 1.00 (Reference) & $0.656(0.306 \sim 1.405)$ & $0.335(0.145 \sim 0.773)^{*}$ \\
Reduced HDL-C & 1.00 (Reference) & $0.656(0.285 \sim 1.508)$ & $0.328(0.126 \sim 0.852)^{*}$ \\
Increased blood pressure & 1.00 (Reference) & $0.518(0.214 \sim 1.255)$ & $0.678(0.288 \sim 1.599)$ \\
Elevated fasting blood sugar & 1.00 (Reference) & $0.794(0.284 \sim 2.222)$ & $0.604(0.201 \sim 1.813)$ \\
Metabolic syndrome & 1.00 (Reference) & $0.333(0.079 \sim 1.400)$ & $1.083(0.351 \sim 3.344)$ \\
\hline
\end{tabular}

Adjusted odds ratios for metabolic components and metabolic syndrome. Adjusted for age and gender. "; $P<0.05$. Abbreviation: HRR, heart rate recovery; HDL-C, high density lipoprotein cholesterol. 
은 중성지방은 심박수 회복 제 1 삼분위수보다 제 3 삼분위수 에서 0.34 배(95\% CI: 0.145 0.773) 낮은 유병률을 나타냈다 $(P<0.005)$. 또한 낮은 $\mathrm{HDL}$-콜레스테롤은 심박수 회복의 제 1 삼분위수보다 제 3 삼분위수에서 0.33 배 $(95 \%$ CI: 0.126 $0.852)$ 낮은 유병률을 보였다 $(P<0.005)$.

\section{고 찰}

한국성인을 대상으로 한 이 연구결과 $\mathrm{MHO}$ 군은 $\mathrm{MHNO}$ 군과 비교하여 미주신경 활성도에 차이가 없었으나, MUO 군은 늦은 심박수 회복을 보여 미주신경 활성도가 낮았다. 심박수 회복은 $\mathrm{BMI}$, 허리둘레, 중성지방, $\mathrm{HbA1c}$, 인슐린, 요산과 역상관 관계를 보였다. 또한 심박수 회복은 대사증 후군 구성요소 중 복부비만, 고중성지방혈증, 낮은 $\mathrm{HDL}-$ 콜레스테롤혈증을 예측하는 유용한 지표임을 확인하였다.

대사적으로 건강한 비만인은 대사적으로 이상이 있는 비만인에 비해 높은 인슐린 감수성과 고혈압, 이상지질혈 증, 염증 반응 등 대사적 이상의 발생빈도가 낮은 것으로 알려져 있다(Primeau et al., 2011). 특히 교감신경의 활성도 증가와 부교감신경의 활성화 감소에 의한 자율신경계 기 능장애는 비만인에서 자주 발견되며 인슐린 저항성, 중심 성 비만, 시상하부의 염증, 심폐체력 저하의 결과로 추정 되고 있다(Rodríguez-Colón et al., 2011; Zhu et al., 2016; Jais and Brüning, 2017). 자율신경계 및 심혈관계 기능의 평가 는 심박동수 변이 및 압력수용체 민감도(baroreceptor sensitivity)로 추정할 수 있으나, 측정의 간편성 때문에 심박 수 회복을 흔히 사용한다(Cole et al., 1999). 운동선수나 건 강인은 운동 후 심박수 회복 반응이 빠르게 나타나며, 느 린 심박수 회복은 고혈압, 당뇨병 및 심혈관질환의 위험 을 예측하는 지표로 제시된다(Imai et al., 1994; Cole et al., 1999; Nishime et al., 2000).

본 연구결과 $\mathrm{MHO}$ 군과 $\mathrm{MUO}$ 군간에 심박수 회복은 차 이가 없었으나, MHNO군보다 MUO군에서 늦은 심박수 회복 반응을 나타냈다. 이는 대사증후군을 동반한 비만성 인에서 심박수 회복으로 평가된 자율신경 기능장애가 존 재함을 암시하는 결과이다. 또한 비만인에서 심박수 회복 은 대사지표 중 BMI, 허리둘레, 중성지방, $\mathrm{HbAlc}$, 인슐린, 요산과 유의한 역상관 관계를 보였다. 최근 연구에서 심 박수 회복의 감소는 BMI가 높을수록 영향을 받으며, 대 사적으로 건강한 비만 아동보다 대사적으로 이상이 있는 비만 아동에서 심박수 회복으로 평가한 자율신경계 기능 장애가 존재함을 확인하였다(Bjelakovic et al., 2017). 또한
$\mathrm{MHO}$ 군은 $\mathrm{MUO}$ 군과 비교하여 심혈관계질환 및 사망 위 험이 낮으며, $\mathrm{MHNO}$ 군과 비교하여도 위험이 높지 않은 것으로 보고된다(Phillips, 2013; Stefan et al., 2013; Blüher, 2014; Samocha-Bonet et al., 2014). 또 다른 연구에서는 $\mathrm{MHO}$ 군에서 현저하지는 않으나 잠재적인 심혈관질환 위 험과 대사장애를 내포하고 있어 체중만으로 건강 상태를 파악하는 것의 부적합성을 보고하였다(Hong et al., 2012; Shin et al., 2017). 이러한 결과들을 종합하면 비만하더라도 대사적 상태에 따라 비만의 중재적 접근을 달리해야 하며, 잠재적인 심혈관계를 평가하는데 비만 상태뿐만 아니라 대사적 이상 유무를 동시에 고려하는 것이 중요함을 의 미한다. 그러나 피험자의 건강 상태는 $\mathrm{MHO}$ 군에서 $\mathrm{MUO}$ 군으로 전환될 수 있으며, 그 반대도 전환될 수도 있다. 예컨대, Soriguer 등(2013)은 6년간의 추적관찰 결과 $\mathrm{MHO}$ 의 30 40\%가 MUO로 전환된 것을 확인하였다. Adelaide Health Study에서는 5.5 10.3년의 추적관찰 기간 동안 $\mathrm{MHO}$ 표현형을 보였던 개인의 약 $1 / 3$ 이 MUO 표현형으로 전환되어 $\mathrm{MHO}$ 표현형은 정적인 상태가 아니라는 것을 증명하였다(Appleton et al., 2013). 본 연구에서 심박수 회 복은 제 1 삼분위수보다 제 3 삼분위수에서 복부비만, 고중 성지방혈증, 낮은 $\mathrm{HDL}$-콜레스테롤혈증의 유병률이 낮게 나타나 심박수 회복이 대사증후군 구성요소 중 복부비만, 고중성지방혈증, 낮은 HDL-콜레스테롤혈증을 예측하는 유용한 지표임을 확인하였다. 자율신경계 기능장애는 심 혈관계 위험 증가 및 사망률과 관련이 있으므로 심혈관계 위험을 평가하기 위해서는 비만인의 심박수 회복을 측정 함으로써 자율신경계 기능을 정량화할 필요성이 있겠다 (Bjelakovic et al., 2017). 그러나 이러한 목적을 위해서는 심 박수 회복을 평가하는 프로토콜의 표준화와 표적 장기손 상의 위험을 예측하는 심박수 회복의 적정 절단값에 대한 검토가 요구된다(Bjelakovic et al., 2017).

본 연구는 횡단면 연구로 인과관계를 규명하는데 어려 움이 있으며, 가족력, 음주, 흡연, 운동습관 등의 자료부족 으로 연구에서 고려하지 못하였다. 그러나 본 연구는 한 국인을 대상으로 비만 표현형에 따른 심박수 회복 반응 의 차이와 심박수 회복과 대사지표간의 관련성 및 심박수 회복의 대사증후군 예측능력을 확인한 연구로 의미가 있 겠다.

\section{ACKNOWLEDGEMENTS}

None. 


\section{CONFLICTS OF INTEREST}

The authors declare no conflicts of interest.

\section{REFERENCES}

Appleton SL, Seaborn CJ, Visvanathan R, Hill CL, Gill TK, Taylor AW, Adams RJ; North West Adelaide Health Study Team. Diabetes and cardiovascular disease outcomes in the metabolically healthy obese phenotype: a cohort study. Diabetes Care. 2013. 36: 2388-2394.

Berntson GG, Norman GJ, Hawkley LC, Cacioppo JT. Cardiac autonomic balance versus cardiac regulatory capacity. Psychophysiology. 2008. 45: 643-652.

Bjelakovic L, Vukovic V, Jovic M, Bankovic S, Kostic T, Radovanovic D, Pantelic S, Zivkovic M, Stojanovic S, Bjelakovic B. Heart rate recovery time in metabolically healthy and metabolically unhealthy obese children. Phys Sportsmed. 2017. 45: 438-442.

Blüher M. Are metabolically healthy obese individuals really healthy? Eur J Endocrinol. 2014. 171: R209-219.

Cole CR, Blackstone EH, Pashkow FJ, Snader CE, Lauer MS. Heart-rate recovery immediately after exercise as a predictor of mortality. N Engl J Med. 1999. 341: 1351-1357.

Curtis BM, O'Keefe JH Jr. Autonomic tone as a cardiovascular risk factor: the dangers of chronic fight or flight. Mayo Clin Proc. 2002. 77: 45-54.

Deurenberg P, Yap M, van Staveren WA. Body mass index and percent body fat: a meta analysis among different ethnic groups. Int J Obes Relat Metab Disord. 1998. 22: 1164-1171.

Dorresteijn JA, Visseren FL, Spiering W. Mechanisms linking obesity to hypertension. Obes Rev. 2012. 13: 17-26.

Expert Panel on Detection, Evaluation, and Treatment of High Blood Cholesterol in Adults. Executive Summary of The Third Report of The National Cholesterol Education Program (NCEP) Expert Panel on Detection, Evaluation, And Treatment of High Blood Cholesterol In Adults (Adult Treatment Panel III). JAMA. 2001. 285: 2486-2497.

Grundy SM. Obesity, metabolic syndrome, and cardiovascular disease. J Clin Endocrinol Metab. 2004. 89: 2595-2600.

Guilkey JP, Dykstra B, Erichsen J, Mahon AD. Heart Rate Response and Variability Following Maximal Exercise in Overweight Children. Pediatr Exerc Sci. 2017. 29: 341-349.

Hong SB, Shin KA, Choi WS. Comparison of Echocardiogram and Clinical Profile between Metabolically Healthy Obese (MHO) and Non Metabolically Healthy Obese (Non-MHO) Subjects. Biomedical Science Letters. 2012. 18: 260-267.

Imai K, Sato H, Hori M, Kusuoka H, Ozaki H, Yokoyama H, Takeda $\mathrm{H}$, Inoue M, Kamada T. Vagally mediated heart rate recovery after exercise is accelerated in athletes but blunted in patients with chronic heart failure. J Am Coll Cardiol. 1994. 24: 1529 -1535 .

Jais A, Brüning JC. Hypothalamic inflammation in obesity and metabolic disease. J Clin Invest. 2017. 127: 24-32.

Kim J, Byun W, Sui X, Lee DC, Cheng YJ, Blair SN. Heart rate recovery after treadmill exercise testing is an independent predictor of stroke incidence in men with metabolic syndrome. Obes Res Clin Pract. 2011. 5: e267-360.

Libby P, Ridker PM, Maseri A. Inflammation and atherosclerosis. Circulation. 2002. 105: 1135-1143.

Licht CM, de Geus EJ, Penninx BW. Dysregulation of the autonomic nervous system predicts the development of the metabolic syndrome. J Clin Endocrinol Metab. 2013. 98: 2484 $-2493$.

Lim S, Shin H, Song JH, Kwak SH, Kang SM, Won Yoon J, Choi SH, Cho SI, Park KS, Lee HK, Jang HC, Koh KK. Increasing prevalence of metabolic syndrome in Korea: the Korean National Health and Nutrition Examination Survey for 19982007. Diabetes Care. 2011. 34: 1323-1328.

Nishime EO, Cole CR, Blackstone EH, Pashkow FJ, Lauer MS. Heart rate recovery and treadmill exercise score as predictors of mortality in patients referred for exercise ECG. JAMA. 2000. 284: 1392-1398.

Oh SW, Im JW, Lee JW, Kim KW, Choi JK, Park MS, Yoo TW. What are the Characteristics of Obese Adults without Metabolic Complications? J Korean Acad Fam Med. 2006. 27: 733-740.

Peçanha T, Silva-Júnior ND, Forjaz CL. Heart rate recovery: autonomic determinants, methods of assessment and association with mortality and cardiovascular diseases. Clin Physiol Funct Imaging. 2014. 34: 327-339.

Phillips CM. Metabolically healthy obesity: definitions, determinants and clinical implications. Rev Endocr Metab Disord. 2013. 14 219-227.

Primeau V, Coderre L, Karelis AD, Brochu M, Lavoie ME, Messier V, Sladek R, Rabasa-Lhoret R. Characterizing the profile of obese patients who are metabolically healthy. Int J Obes (Lond). 2011. 35: 971-981.

Rodríguez-Colón SM, Bixler EO, Li X, Vgontzas AN, Liao D. Obesity is associated with impaired cardiac autonomic modulation in children. Int J Pediatr Obes. 2011. 6: 128-134. 
Samocha-Bonet D, Dixit VD, Kahn CR, Leibel RL, Lin X, Nieuwdorp M, Pietiläinen KH, Rabasa-Lhoret R, Roden M, Scherer PE, Klein S, Ravussin E. Metabolically healthy and unhealthy obese--the 2013 Stock Conference report. Obes Rev. 2014. 15: 697-708.

Shetler K, Marcus R, Froelicher VF, Vora S, Kalisetti D, Prakash M, Do D, Myers J. Heart rate recovery: validation and methodologic issues. J Am Coll Cardiol. 2001. 38: 1980-1987.

Shin KA. Association of metabolic syndrome with exercise capacity and heart rate recovery after treadmill exercise test. Biomedical Science Letters. 2011. 17: 305-311.

Shin S, Kim JM, Sung S, Kim HS. Prevalence and associated characteristics of metabolically healthy obese phenotypes in a community dwelling population. J Obes Metab Syndr. 2017. 26: 130-137.

Singh K, Shen BJ. Abdominal obesity and chronic stress interact to predict blunted cardiovascular reactivity. Int J Psychophysiol. 2013. 90: 73-79.

Soriguer F, Gutiérrez-Repiso C, Rubio-Martín E, García-Fuentes E, Almaraz MC, Colomo N, Esteva de Antonio I, de Adana MS, Chaves FJ, Morcillo S, Valdés S, Rojo-Martínez G. Metabolically healthy but obese, a matter of time? Findings from the prospective Pizarra study. J Clin Endocrinol Metab. 2013. 98: 2318-2325.

Stefan N, Häring HU, Hu FB, Schulze MB. Metabolically healthy obesity: epidemiology, mechanisms, and clinical implications. Lancet Diabetes Endocrinol. 2013. 1: 152-162.

Yu TY, Jee JH, Bae JC, Hong WJ, Jin SM, Kim JH, Lee MK. Delayed heart rate recovery after exercise as a risk factor of incident type 2 diabetes mellitus after adjusting for glycometabolic parameters in men. Int J Cardiol. 2016. 221: 17-22.

World Health Organization. The Asia-Pacific Perspective: Redefining obesity and its treatment. Sydney, Australia: Health Communications Australia. 2000.

Zhu L, Zhao X, Zeng P, Zhu J, Yang S, Liu A, Song Y. Study on autonomic dysfunction and metabolic syndrome in Chinese patients. J Diabetes Investig. 2016. 7: 901-907.

https://doi.org/10.15616/BSL.2018.24.3.245

Cite this article as: Shin KA. Heart Rate Recovery in Metabolically Healthy Obesity and Metabolically Unhealthy Obesity Korean Adults. Biomedical Science Letters. 2018. 24: 245-252. 